\title{
LA HISTORIA DE LA ENFERMERÍA: PRESENCIAS Y AUSENCIAS EN LA ENFERMERÍA URUGUAYA
}

\author{
The History of Nursing: \\ Presences and absences in Uruguayan Nursing \\ A História da Enfermagem: \\ Presenças e Ausências na Enfermagem Uruguaia
}

Nidia Hernández Suárez

\begin{abstract}
Resumen
El tema se refiere a la historia de la enfermería y su relación con el desarrollo de la profesión y la actividad de investigar desde la etapa de profesionalización, en el siglo diecinueve, así como la inserción de la enfermería en la universidad. Objetivo: Se busca conocer cuál es la situación de la Historia de la Enfermería Uruguaya como línea de investigación, qué aspectos la incentivan y promueven y cuál la incidencia en el desarrollo del pensamiento enfermero. Se trata de un abordaje cualitativo en el marco de un sondeo exploratorio dirigido a una muestra intencional de 9 enfermeras, socias del Colegio de Enfermeras del Uruguay. Mediante el envío, vía electrónica, de un instrumento guía, se obtuvo la respuesta de 5 enfermeras. Se constata que la Historia de la Enfermería tiene escasa representatividad a causa de la ausencia en el currículum de grado y postgrado, así como el limitado número de publicaciones. Se agrega información valiosa que debe ser tenida en cuenta. Los contenidos procesados en los resultados orientan a la realización de un estudio de mayor dimensión y profundidad.
\end{abstract}

Palabras clave: Enfermería Historia Investigación.

\begin{abstract}
The Theme refers to the history of nursing and its relationship with the professional development and the activity of investigating since the professional stage, in the nineteenth century, as well as the insertion of nursing at the university. The objective try to find out the History of Uruguayan Nursing situation as a line of investigation, which aspects encourage and promote it and what is the incidence in the nursing thinking development. The methodology it is a qualitative attempt, within an exploratory survey frame, aimed towards an intentional sample of nine nurses, members of the Nurses' College of Uruguay. Through sending, by e-mail, a guideline instrument, we obtained the responses of five nurses. The results were verified that the History of Nursing has scarce representation due to the absence in the degree and post-degree curriculum, as well as for the limited number of publications. Attached is valuable information that must be considered. The conclusions find out that the processed contents advises towards achieving a study of greater and deeper dimension.
\end{abstract}

Keywords:

Nursing. History. Research.

\section{Resumo}

0 tema refere-se à história da enfermagem e sua relação com o desenvolvimento da profissão e com a atividade de pesquisar desde a etapa da profissionalização, no século dezenove, assim como à inserção da enfermagem na universidade. Objetivo: A intenção é conhecer qual é a situação da História da Enfermagem Uruguaia como processo de pesquisa, quais os fatores que a incentivam e promovem e qual a sua incidência no desenvolvimento do pensamento da enfermagem. Trata-se de uma abordagem qualitativa no marco da uma sondagem exploratória dirigida a uma amostra intencional de 9 enfermeiras, sócias do Colégio de Enfermeiras do Uruguai. Mediante o envio, por meio eletrônico, de um instrumento-guia, obteve-se a resposta de 5 enfermeiras.Constata-se que a História da Enfermagem possui escassa representatividade devido à sua ausência nos currículos de graduação e pós-graduação, assim como pelo limitado número de publicações. Acrescenta-se informação valiosa que deve ser apreciada. Os conteúdos processados nos resultados orientam à realização de um estudo de maior dimensão e profundidade.

Palavras-chave:

Enfermagem. História. Pesquisa. 


\section{INTRODUCCIÓN}

La investigación en Historia de la Enfermería tiene una estrecha relación con el desarrollo de la profesión en general y con la propia actividad de investigar en particular. El abordaje del tema comienza por indagar sobre qué lugar ocupa la investigación en el hacer enfermero en el contexto mundial y cuál el de la historia como línea de investigación. Para contextualizar el trabajo se toma como referente la publicación del Consejo Internacional de Enfermería, CIE, con motivo de conmemorar sus 100 años de creación, Londres $1999^{1}$.

Considerando que la enfermería es una profesión legitimada a nivel universal, que la investigación es un elemento ineludible en tanto disciplina, en la que los estudios históricos ocupan un determinado lugar, se propone a partir de la documentación señalada establecer un marco de referencia al tema Historia de la Enfermería en Uruguay.

El objetivo de la comunicación se centra en conocer la situación de la historia de la enfermería uruguaya en base a las publicaciones efectuadas y su presencia o no en los diferentes estadios de la formación de profesionales de enfermería. Se busca indagar qué aspectos promueven e incentivan la investigación histórica desde la formación de grado y su relación con el avance del pensamiento enfermero.

Para responder éstos cuestionamientos partimos de la idea que la disciplina enfermera, en tanto objeto de enseñanza y aprendizaje es una ciencia en construcción en busca de un paradigma consolidado. Como disciplina surge a mediados del siglo diecinueve. Aunque no debe desconocerse la importancia de la evolución del pensamiento y el hacer científicos que avanzan a partir del siglo diecisiete. En el siglo diecinueve es evidente la influencia que ejercen en la enfermería los sistemas políticos, de salud en el ámbito laico o religioso y de educación, todo lo que dará sustento a la corriente positivista.

El cambio en la concepción de los hospitales, no sólo para atender desvalidos sino para apoyar el proceso de aprendizaje de la medicina, creó la necesidad de mejorar la práctica de las mujeres que cuidan.

Entorno al que no estuvo ajena Forence Nightingale con la insistencia en el valor de la observación, el registro, las cifras, elementos que pusiera en práctica para fundamentar algunas de sus ideas transformadas en propuestas, aspecto que podemos considerar como los primeros indicios de investigación e imagen de profesionalismo.

El espacio en que se inserta la difusión del pensamiento científico de la época sigue la ruta del poderío económico inglés, no sólo desde el imperio real, India, África, Canadá,
Estados Unidos, Oriente Lejano, sino el imperio informal que inclúa América Latina 2:63. Una política que vinculada al cambio social y el apoyo del protagonismo incipiente, pero sostenido, que estaba adquiriendo el mundo de la mujer, trasladó su cultura y en ella y con ella, también, el saber y el hacer enfermero reflejado en el conocimiento y la práctica en su etapa de transición del cuidado empírico-comprensivo a la conversión en objeto de aprendizaje y enseñanza.

La literatura enfermera coincide en que la investigación en enfermería es relativamente nueva constatándose que la inserción de la profesión en la Universidad, fenómeno de nivel internacional, jugó un papel preponderante. El concepto de disciplina enfermera se complementa con la incorporación de otros atributos como el conocimiento, las habilidades y los principios éticos.

Se tiene en cuenta el origen y evolución de la universidad en occidente, que muestra elementos comunes que la identifican como el ámbito destinado a la reflexión y el arte de la crítica. La UNESCO reconoce en ella la misión tradicional de mantener, incrementar y difundir el conocimiento a través de la investigación y creación intelectua ${ }^{\beta}$. En éste sentido la investigación es el eje que orienta la producción del conocimiento en el que se apoya, así como la difusión de sus hallazgos, resultados y avances, elemento imprescindible en el ciclo de relación universidad-sociedad.

La evolución de la investigación en enfermería planteada por Polit y Hungler ${ }^{4: 5}$, en los Estados Unidos, sin querer hacer un paralelismo con otras realidades, permite advertir que el proceso se dio en etapas. Los primeros estudios se vincularon a cómo era la formación de enfermería, aspecto que sirvió de fundamento para apoyar la inserción en el ámbito universitario. A partir de la Segunda Guerra Mundial, década de 1940 el avance de la investigación es notable.

Para Collier 5:194, la formación universitaria, inicia el caminar interrogativo, obliga al cuestionamiento, conduce a la argumentación. Como consecuencia, las enfermeras comienzan a construir un patrimonio de textos que no incluyen sólo manuales técnicos sino artículos de moral y ética profesional.

La necesidad de la enfermería de responder preguntas, no sólo sobre el cuidar, sino de descubrir los fundamentos de la propia profesión y ahondar sobre el sujeto del cuidado, en su singularidad dentro de la complejidad como ser humano, dio lugar al pensamiento crítico sistemático. Una realidad que se impone desde la formación de grado en un ejercicio de relación y búsqueda de los porqués que sustentan las acciones.

Pero el verdadero avance generado en los últimos años responde a la incorporación en escala ascendente de la formación superior, especialmente asumida en 
América Latina, por las grandes Universidades públicas dada su necesaria vinculación con otros sectores de la construcción del tejido social del conocimiento y la innovación en la búsqueda de un mundo mejor ${ }^{6}$.

Según la fuente de consulta ya mencionada, la investigación en enfermería ubica en Europa, en primer lugar al Reino Unido seguido por España y Suecia, así como Estados Unidos, Canadá y Brasil en las Américas".

No en vano ambos continentes son ámbitos de difusión y socialización de la producción investigativa en enfermería, en Coloquios y Congresos llevados a cabo en forma bianual. Tal la Conferencia Bienal del Grupo de Trabajo de las Enfermeras Europeas, desde 1992 y el Coloquio Panamericano de Investigadores en Enfermería desde sus inicios en 1996.

Éstos antecedentes refuerzan la percepción de Peter Drucker, economista y eminente filósofo vienés, creador de una nueva actitud en la gestión, que ha expresado que "ninguna disciplina ha producido tantos y tan relevantes conocimientos, en los últimos años como la enfermería", cita tomada por Silvina Malvárez como referente en diversas conferencias.

A pesar de ello se infiere que el horizonte en el concierto mundial, está lejano y sus manifestaciones son desiguales ${ }^{1}$. Crear una cultura investigadora parte del interés en el saber y el querer ${ }^{\text {7:72 }}$ de cada persona, enfermera o no, que nace y se potencia desde los primeros años del ciclo educativo cuando la maestra-profesora del niño-adolescente los estimula en el gusto por descubrir.

En la formación universitaria se transforma en una actividad integrada y sistemática que distingue como tal a cada disciplina según su campo de conocimiento.

Sin embargo otros elementos hacen falta para desarrollar ésa cultura, al interés y al querer se suma la disposición en la búsqueda del tiempo-espacio en el accionar cotidiano, en éste caso de las enfermeras, variado en demandas y compromisos. Aún si así lo hubiere, la investigación en cualquier disciplina se encuentra inmersa en el contexto estructural de cada país en una relación dialéctica inevitable entre las políticas de Estado, el enfoque de la Educación Superior y el desarrollo económico y social.

De ahí que el saber y el querer ${ }^{6: 72}$, para poder hacer, no son sólo eso, necesitan el soporte institucional en el sentido más amplio, de lo contrario se puede saber pero no se puede lograr querer investigar.

La comunidad enfermera en un necesario y cada vez más intenso indagar sobre el sustento teórico de la disciplina ha avanzado en el pensamiento filosófico, científico, tecnológico que hace al distintivo de su actividad específica, objetivado a través del hacer como el resultado del conocimiento y el arte de cuidar en salud y enfermedad al ser humano en tanto sujeto cultural, en una relación de intercambio con la sociedad y el medio ambiente.

En éste sentido el hacer se genera y hace visible mediante elementos que definen el ser enfermero en un ritmo dinámico de construcción-deconstrucción con una dimensión existencial de ser ahí sólo posible si es ser con otros a la manera de Heidegger 8:136.

El devenir, como venir a ser se construye y se transforma a partir de un punto de inflexión donde se cruzan las coordenadas del tiempo y el espacio en el que están inmersas las acciones humanas, figura que sintetiza nuestra visión de la Historia. A la vez que incorpora la vida tradicional que sirve de fondo permanente a la historia cambiante y visible como definiera Miguel de Unamuno a lo que él llamó Intrahistoria 9:1183.

La inclusión de la Historia como línea de investigación en enfermería nos conduce a incursionar en una expresión emblemática, en tanto representación simbólica a nivel mundial, como la Conferencia del Consejo Internacional de Enfermeras, CIE, Londres 19991. Una amplia convocatoria congregó Enfermeras de las Asociaciones miembros de todo el mundo, a la que se enviaron más de 2000 resúmenes de ponencias, seleccionándose 795.

El Programa de Disertaciones de Participantes, Simposios y Presentación de Posters ${ }^{1}$ consignan que del total de 795 resúmenes publicados, corresponden al área Clínica un 57,61\% y a la No Clínica un 42,39\%.

La línea Historia inserta en el área No Clínica suma 39 trabajos (12\%), que se distribuyen según idiomas oficiales en un $92,3 \%$ en inglés, $2,5 \%$ en francés y $5,2 \%$ en español. En síntesis del total de resúmenes solamente el 5\% están dentro de la línea Historia, aunque el evento tenía como lema convocante la conmemoración de un acontecimiento vinculado a los orígenes y trayectoria de la propia Institución.

La enfermería en tanto objeto de investigación histórica ha tenido un incremento en los últimos 20 años, según la realidad de cada país, mediante la inclusión como adicional, introductoria o complementaria en los programas de formación de grado, contribuyendo a la generación de una cultura profesional enfermera. Las disciplinas en la que se inserta son variadas, tal Legislación, Problemas Profesionales, Arte de Enfermería, Enfermería Clínica, Deontología, Epistemología, Introducción a la Enfermería, Fundamentos de Enfermería, Enfermería Fundamental. Pero la clave está en los efectos de la inclusión temprana como elemento sensibilizador más allá de la variable, y en general discreta carga horaria. El impulso mayor se observa a nivel de postgrado, incluida en el marco teórico y luego tratada como tema de tesis. 
Tomando como guía las ponencias del $1^{\circ}$ Coloquio Latino Americano de Historia de la Enfermería, Río de Janeiro, 2000, se deducen condicionantes que inciden en diversos sentidos, como la legitimación de la enseñanza de la historia en el plan de estudios mediante instrumentos legales ${ }^{10: 321}$.

Propuestas creativas con un enfoque metodológico desde actividades prácticas, en el marco de otra materia como Introducción a la Enfermería, buscan comprometer al alumno en. La socialización del conocimiento de los orígenes y trayectoria de la enfermería, entre familiares y amistades ${ }^{11: 359}$.

La realidad de Uruguay está signada por la trayectoria que la propia enfermería profesional ha tenido desde sus orígenes. El hecho más relevante en la primera mitad del siglo veinte, lo constituye el decreto del Poder Ejecutivo del 23 de octubre de 1911 mediante el cual se crea la primera Escuela de Enfermería, más bien de Nurses como se la denominara ${ }^{12: 52}$.

La Escuela se implementa en 1912, según modelo Nightingale, dependiente de la Asistencia Pública Nacional, con instructoras inglesas y un director médico, el Dr. Carlos de Oliveira Nery.

La década de los años 40 y los cambios a nivel mundial incidieron fuertemente en el contexto latinoamericano. En lo local la necesidad de poner en funcionamiento el Hospital de Clínicas, en el ámbito de la Universidad de la República con la finalidad de brindar asistencia, docencia y desarrollar la investigación, llevó a proponer y aprobar la creación de la Escuela Universitaria de Enfermería, dependiente de la Facultad de Medicina. Así fue como el 2 de mayo de 1950 se inaugura dicha Escuela, coexistiendo con la Escuela de Nurses Dr. Carlos Nery. A partir de 1985 y luego del período de clausura decretado por el gobierno de facto (1973-1984), se reabre la Escuela Universitaria de Enfermería como única Escuela pública para la formación de profesionales en enfermería.

En el transcurso de 56 años de la Escuela Universitaria de Enfermería (1950-2006), la Historia de la Enfermería no tuvo inserción expresa en el currículum. Hasta la clausura en 1973, había sido enfocada por enfermeras docentes con afinidad hacia el tema, sin continuidad luego de la reapertura.

En el comienzo del siglo veintiuno se produce la edición de los tres primeros libros de investigación en Historia de la Enfermería: Historia de la Enfermería. Aspectos relevantes desde los orígenes hasta el siglo XX, 2002, Historia de la Enfermería en Uruguay, 2002 y Ana Packer, construyendo el saber y hacer enfermero. De Inglaterra a Cuñapirú-Corrales. 1841-1930., 2004.

\section{METODOLOGÍA}

La percepción de la inclusión de la Historia de la Enfermería a diferentes niveles en Latino América, nos movió a indagar sobre la presencia y/o ausencia de la misma en la enfermería uruguaya. Para responder a éste cuestionamiento y buscando obtener una visión general y aproximada sobre el tema, dado los escasos registros existentes sobre el particular, se realizó un sondeo exploratorio ${ }^{13: 62}$.

Los ejes orientadores fueron enunciados en forma de propuestas abiertas, de libre interpretación.

Los contenidos señalan:

-Explorar la percepción de las enfermeras respecto a la Historia de la enfermería como línea de investigación.

- Conocer qué aspectos la incentivan y cuales la promueven, y

- Conocer qué incidencia puede tener la presencia o no de la historia de la enfermería en el desarrollo del pensamiento enfermero.

Se seleccionó una muestra intencional integrada por 9 enfermeras, socias del Colegio de Enfermeras del Uruguay, (CEDU), cursando diferentes momentos de su ciclo vital y profesional: 3 docentes, 3 cursantes de maestría y 3 graduadas en situación de retiro laboral.

El estudio de corte cualitativo se realizó mediante un instrumento-guía cuyo contenido tenía por finalidad orientar la definición de categorías siguiendo un procedimiento inductivo ${ }^{14: 210}$. El instrumento, auto administrado y enviado por vía electrónica contenía, a modo de introducción, la finalidad de la propuesta y estatus de las integrantes de la muestra. Se agradecía la colaboración de cada una respondiendo en forma libre, así como aportando sugerencias sobre el planteamiento efectuado. Éste enfoque tiene la ventaja, para quien responde, que consigna por sí mismo su opinión sin contar con la interacción del entrevistador lo que le da libertad y mayor posibilidad de calidad ${ }^{13: 175}$.

La propuesta fue autorizada por el Consejo Directivo del Colegio de Enfermeras del Uruguay.

La recolección de datos se llevó a cabo durante el mes de abril de 2005. De las 9 enfermeras seleccionadas respondieron 5 , una se excusó de no poder hacerlo, otra anunció que lo haría en conjunto con sus compañeras, pero no lo hizo y dos no acusaron recibo de la guía de orientación. A excepción de la que respondió negativamente, a las demás se le reenvió el mensaje en dos oportunidades más. Las cifras denotan un $45 \%$ de no respuestas. Según Pourtois 15:185 se considera razonable que los que no contestan no supere el $15 \%$ a $20 \%$. Debido al tiempo preestablecido no se consideró la sustitución por otras enfermeras. 
De las respondientes, 3 corresponden a la categoría: en retiro laboral, una a la de cursante de maestría y otra es docente.

En agosto se mantuvo una reunión de socialización-validación de los resultados con la presencia de 3 integrantes. La ausencia de una de ellas se debió a motivos de salud y de la otra a ocupaciones laborales y tiempo de traslado en función de la distancia al lugar de la presentación. Se dio lectura a la ponencia que sería presentada en el $2^{\circ}$ Coloquio de Historia de la Enfermería, Escuela de Enfermería Anna Nery. Universidad Federal de Río de Janeiro, 12 al 15 de setiembre de 2005

En la oportunidad de la presentación de resultados reafirmaron, con énfasis, algunas expresiones.

Para el procesamiento de las respuestas $(R)$ se otorgó un orden numérico preservando la identidad de cada una de las 5 enfermeras que contestaron.

Se realizó una primera lectura obteniendo una visión de conjunto. En sucesivas relecturas se procedió a transcribir los tramos según el sentido de las respuestas procediendo a aislar unidades temáticas. Se tiene en cuenta la formulación de opiniones singulares que tienden a explicar y comprender las razones de los comportamientos que asumen algunas protagonistas ${ }^{16: 79}$, lo que da lugar a incluir una categoría no prevista.

De la simplificación por condensación surgen las siguientes categorías.

1- Inclusión - exclusión de la historia como línea de investigación.

2 - Percepción: relación historia - pensamiento del enfermero.

3 - La historia de la comunidad de enfermería.

\section{RESULTADOS}

En un principio el abordaje del tema pasa por responder si es posible, para cualquier profesión, desconocer el origen y el pasado de la misma, aceptando como respuesta el concepto que una humanidad global que no tuviera ningún conocimiento de su pasado sería tan anormal como un individuo amnésico ${ }^{17: 28}$ Si traemos ésta imagen al escenario de las profesiones sería imposible definir el estado actual de las mismas y menos aún visualizar su futuro. Incluso las palabras hombre $y$ sociedad no tendrían sentido ${ }^{18: 96}$.

Inclusión - exclusión de la historia como línea de investigación

Los recortes extraídos expresan:

Conozco pocos trabajos al respecto [...] no es asunto que despierte interés. R.1.
[...] me he detenido poco o nada para conocer la Historia de la Enfermería y creo que muchas colegas están en la misma situación. R.4

[...] la enfermería como colectivo no se ha encontrado aún con la importancia que implica la investigación histórica en la construcción de su quehacer. R.3.

[...] una gran parte de las profesionales caminan por la vida laboral sin hacerse aquéllas preguntas, ¿quién soy?, ¿de dónde vengo?,¿ hacia dónde voy?... olvidando que ésas preguntas clave nos las hacíamos de chicos [...] R.2.

Las palabras señalan la percepción de un fenómeno generalizado desde la visión personal de las respondientes. El tema se profundiza y explica en los siguientes aportes.

[...] la enfermería de hoy le resta importancia. R.5 [...] en mi formación profesional no existió la suficiente información y reflexión sobre éste tema. R.4.

[...] en los centros formadores no existe aún la cátedra de Historia de la Enfermería. R.2.

[...] para tomar la historia como línea de investigación existen carencias en la formación profesional en ésta área. R.3.

Se desprende una aparente falta de interés cuyos condicionantes se advierten en la no percepción de la importancia de la Historia en la construcción de lo que identifica y distingue a la Enfermería como disciplina. Aspectos que refuerzan la alusión a la ausencia de la historia en la formación de grado, poniendo en evidencia la dificultad de ser sensible a algo que no se conoce.

Las siguientes apreciaciones consideran incentivos para la inclusión del tema tales como:

[...] a partir de los trabajos de tres enfermeras conocimos otros aspectos que resultan interesantes. R.1.

Comenzó el siglo con un buen augurio [...] la edición de tres libros de la Historia de la Enfermería en Uruguay. R. 2.

La producción histórica en el país aunque pequeña puede ser uno de los estímulos. R.3. Creo que sin duda las acciones que la promueven es la búsqueda de principios éticos y valores en la práctica enfermera, que van de la mano con nuestra historia y con nuestro futuro. R.4.

La visión positiva ante una incipiente edición de estudios históricos crea un nexo de transparencia entre la profesión y el colectivo, cuya vía es la comunicación que fusiona en un mismo y recíproco nivel al hombre y la sociedad y que se vivencia como estimulante 19:62.

Resalta otro elemento positivo desde una visión reflexiva. 
Plantearnos la historia como línea de investigación significa encontrar lo que no hay que repetir porque no fue bueno, pero rescatar y transformar para continuarlo...R.3.

También se ve como

Un modo de repensar, sentir y actuar en los diferentes momentos históricos, que ofrece oportunidad de recoger de los errores y aciertos del pasado para fortalecer el desarrollo a futuro. R.2

El descubrir los elementos vinculantes entre los hechos y las épocas para interpretar la realidad es reconocer un aprendizaje inevitable cuyo significado preciso es la palabra experiencia ${ }^{20: 38}$.

\section{Percepción:}

relación historia - pensamiento del enfermero

En los comienzos del siglo veintiuno la enfermería plantea con mayor énfasis el rescate de su pasado. Aún así el interés por investigar la propia historia de la profesión, decisión política de carácter emancipador, está ligado a la imagen que cada uno se ha formado en el transcurso de su vida, que conlleva una decisión de autorreflexión y confrontación entre los prejuicios, los límites, los intereses personales y la propia historia individual ${ }^{15: 126}$. Aspectos que no siempre están resueltos en tanto decisión y responsabilidad de asumirlos, más aún si no hay un enfoque pedagógico que guíe el conocimiento y la comprensión.

La información recogida en las palabras de las enfermeras hace constar la incidencia que puede tener el conocimiento de la historia en la evolución del pensamiento a partir del estudio y experiencias de vida de otras enfermeras.

Sin duda nos haría reflexionar sobre nuestros orígenes, el conocer y respetar a cada una de las enfermeras que nos dejaron sus pensamientos y teorías y hacer de la enfermería una profesión. (R.4).

Puede demostrar el pensamiento de las enfermeras que defendieron la profesión pensando en el cuidado del usuario no sólo enfermo sino también sano, las que iniciaron la Enfermería Universitaria en la Escuela [...] las que lo siguieron [... ]la experiencia de La Mina [...] de la cual conozco muy poco [...]y el trabajo comunitario [...] agregando a ello la tarea unificadora de las colegas. R.1.

El reencuentro presencial o documental con el desempeño de enfermeras del pasado desarrolla un sentimiento de solidaridad con las edades ${ }^{18: 47}$. Un camino para comprender el presente abriendo oportunidades para despertar el gusto y el deseo por investigar la propia historia.
El enfoque de la Enfermería desde la historia da lugar a otras expresiones.

Si tomamos conciencia de cuánto importa descubrir lo que hemos perdido y el porqué, lo que hemos incorporado y el para qué [...] con qué metodologías, registros, acercamiento a las poblaciones, pueden aportarnos elementos para construir nuestra identidad. R.3.

Un planteo desde la reflexión sobre el pensar-hacer, que se forma procurando buscar los fundamentos de los cambios desde la visión histórica de una identidad que, aunque dinámica, acompaña el devenir de la profesión.

La identidad no es un producto elaborado ni estático, se construye y se reconstruye según el momento histórico y el contexto en el cual se desarrolla, de ahí que el pasado sigue siendo la herramienta analítica más útil para comprender los cambios ${ }^{20: 31}$

La temática estimuló una mirada en el tiempo y el espacio interior aflorando aspectos que se seleccionaron en tanto cuestionamientos reflexivos, marcando la necesidad de un diálogo más profundo. La búsqueda de respuestas se hace visible en las situaciones identificadas por las participantes.

Me resulta imprescindible conocer qué pasa con el concepto de enfermería, su rol independiente y su relación con el usuario. Siento que hay un desdibujamiento muy grave desde la formación. El perfil se vuelca a los vaivenes del mercado para competir con otras profesiones, fundamentalmente médicos. R.1.

[...] la construcción de un pensamiento enfermero que se acerque más a los cuidados que a curar, ya que hoy en día se trabaja profesionalmente a demanda y prácticamente no nos estamos dedicando a cuidar. R.4.

Estamos, creo, evolucionando desde el cuidado a secretaria del médico. R.5.

Se infiere un llamado a esclarecer la incertidumbre que implica un compromiso no sólo con la profesión como saber sino con los usuarios en el hacer. La función se construye en tanto claridad del rol desde el conocimiento del origen de la profesión, a través de su trayectoria de lo universal a lo nacional. Hecho cuya clave se centra en aislar un par de fuertes componentes: el de género condicionado a la evolución histórica de la sociedad, la familia y el entorno, que adquirió visibilidad en el siglo diecinueve en el que las enfermeras sentaron precedentes. El segundo tiene que ver con el paradigma biomédico y su poder hegemónico, situación en la que la enfermería sigue atrapada.

La demanda por un acercamiento mayor a los cuidados y el desdibujamiento desde la formación de 
grado es un paso para definir los aspectos que hacen a la autonomía, demostrar la capacidad de reivindicar las actividades sustantivas del saber-hacer de la enfermera: cuidar, enseñar, investigar y poner en su lugar la gama de actividades que no hacen a los fundamentos que definen su especificidad y que, aunque necesarios se objetivan en cualquier profesión, como la gestión.

\section{La historia de la comunidad de enfermería}

La necesidad de incorporar la historia como línea de estudio e investigación incluyó apreciaciones que señalan consecuencias favorables para el colectivo.

Conocer, analizar y comprender [...] nuestra historia nos coloca en el país y en el sub sector salud con identidad social [permite] responder cabalmente aquellas preguntas [de los orígenes de cada una] R.2.

La investigación acerca de la Historia de la Enfermería nos fortalecería como comunidad enfermera [...] porque conociendo nuestros orígenes y viendo su evolución en el tiempo podríamos tener un pensamiento más homogéneo. R.4.

Responder los interrogantes conducirá a reflexionar sobre la construcción de la identidad en interacción con los otros, obteniendo como resultado la tan deseada visibilidad social de la enfermería a la vez que la generación del sentimiento de pertenencia ${ }^{21: 212}$. Una identidad que se apoya en los conocimientos y la práctica singular y única que respalda a la profesión y que sólo puede legitimar la sociedad confirmando la necesidad de su existencia

Perciben la historia como un nexo de cohesión interna al estimular la recuperación de la memoria ausente, aspectos que se reafirman en las siguientes expresiones.

[...] creo que llevaría a unirnos más como un colectivo y [no] estar trabajando tan aisladamente unas de otras. R.4.

[...] dentro del colectivo enfermero ofrece oportunidad para sentir seguridad [...] una historia común y compartida, construcción social de las licenciadas, motiva la unidad grupal, alcanza la meta de una sola voz que nace $y$ crece en la diversidad de voces, autónoma, reconocida [con] visibilidad social. R.2.

La literatura enfermera reconoce las dificultades de colaboración dentro del equipo y con sus propias colegas, que se remonta a la época victoriana desde la guerra de Crimea. En aquel momento los conflictos provenían de dos vertientes, una interna, signada por las diferencias religiosas entre las 40 enfermeras integrantes del grupo y la que se daba con los médicos que mantuvieron al principio una actitud de rechazo hacia Florence Nightingale y su equipo.

Situación que de alguna manera ha condicionado la imagen que de la enfermería tienen las propias enfermeras, una actitud de aceptación de una aparente normalidad en el rechazo entre pares y el control 0 manejo por fuerzas ajenas a la profesión que tienen mayor prestigio, poder y posición 22:66. Una de las razones que mantiene las dificultades para hacer aportes con responsabilidad dentro de la profesión sin ver que su poder potencial es mayor cuando se unen y se manifiestan como una sola voz que se reafirma en la siguiente expresión

La carencia de la perspectiva histórica acrecienta los círculos viciosos en los que se mueve el colectivo profesional, tropiezo tras tropiezo...R.2.

En éste sentido la historia se ve como una oportunidad en la medida que apunta a hacer comprender el estado social de sus integrantes señalando el camino para lograr éste llamado a la unión.

\section{A MODO DE CONCLUSIÓN}

De acuerdo a lo expuesto, la historia como línea de investigación, cuenta con escasa representatividad en la enfermería uruguaya, consecuente con la ausencia del tema desde la formación de grado y el limitado y reciente número de publicaciones.

El desconocimiento se manifiesta en la falta de interés y motivación a nivel de las graduadas, que aunque no señalado explícitamente, se deduce por ser la condición que tenían las enfermeras involucradas en éste estudio, reflejándose en la educación posbásica.

Resultan positivas las apreciaciones que valoran la necesidad de conocer el pasado recuperando la memoria y dándole sentido al concepto hombre y sociedad. Una manera de posibilitar y comprender el ser y quehacer enfermero y su proyección en la relación con los usuarios y la comunidad.

Los cuestionamientos destacan el interés en reflexionar sobre aspectos que aluden a la formación profesional y a la imagen que se registra. Otro ángulo que abre la mirada a un necesario e imprescindible estudio.

La necesidad de conocer el pasado se presenta como un elemento integrador de actitudes y saberes, generador de identidad y compromiso, además de una oportunidad para comprender el estado social de sus integrantes y señalar el camino para lograr éste llamado a la unión.

Aún considerando el porcentaje de no respuestas se estima que las respondientes plantearon 
concepciones coincidentes desde un enfoque ético y de autoestima que genera confianza en el resultado.

Se evidencia la necesidad de profundizar el tema a punto de partida de ésta aproximación, incluyendo el estudio sobre el estado de la investigación en enfermería en el país y la inclusión del abordaje de la identidad y la autonomía, que emergen desdibujadas en el ámbito de éste análisis. Aspecto que demanda la elaboración de un proyecto más acabado en cuanto a los objetivos, a la metodología y al alcance con la inclusión de graduados en actividad laboral y no laboral. Enfermeras docentes, con desempeño en campos clínicos y/o comunitarios y estudiantes.

\section{Referencias}

1. Consejo Internacional de Enfermería. Programa de disertaciones de participantes, simposios y presentación de posters. Londres; $199927 \mathrm{jun} / 1^{\circ} \mathrm{jul}$.

2. Hernández $\mathrm{N}$ et al. Ana Packer construyendo el saber y el hacer enfermero: de Inglaterra a Cuñapirú-Corrales (1841-1930). Montevideo: Trilce; 2004.

3. UNESCO. Conferencia Mundial sobre Educación Superior. Documento de trabajo Universidad de la República. Secretaría del rectorado, difundido para su estudio en comisiones de la Asamblea General del Claustro. Montevideo: Udelar; 1998 sept/oct. Mimeo.

4. Polit D. et al. Investigación científica en ciencias de la salud. $5^{\mathrm{a}}$ ed. México (DF): McGraw Hill Interamericana; 1997.

5. Collière MF. Promover la vida. Traducción Loreto Rodríguez Méndez.. Madrid: McGraw Hill Interamericana; 1993.

6. Guarga R. París +5 . Seguimiento o revisión de la Conferencia Mundial sobre Educación Superior de la UNESCO: París, 1998. [on line] 2003 jul. [citado 3 mayo 2005].Disponible en: <http// www.rau.edu.uy/universidad/consultiva/rectorado.

7. Rebellato JL La encrucijada de la ética: neoliberalismo, conflicto norte - sur, liberación. $2^{\mathrm{a}}$ ed. Montevideo: Nordam Comunidad; 2000

8. Heidegger M. El ser y el tiempo. Traducción de José Gaos. $5^{2}$ edReimpresión. Buenos Aires: Fondo de Cultura Económica de Argentina; 2004.

9. Real Academia Española. Diccionario de la Lengua Española. $21^{\text {a }}$ ed. Madrid: Espasa-Calpe; 2000. Intrahistoria; p.1183.

10. Tolstenko L. 0 ensino de história da enfermagem e o resgate da memória: panorama nos cursos de enfermagem da região nordeste. Esc. Anna Nery Rev Enferm 2000 dez; 4(3): 321-32.

11. Oguisso Taka. Memória e história: Centro Histórico-Cultural da Enfermagem Ibero-Americana. Esc Anna Nery Rev Enferm 2000 dez; 4(3): 359-67.
La disposición de las participantes a aportar opiniones y sugerencias sobre el sondeo exploratorio, planteada en el instrumento guía, consignan las siguientes apreciaciones.

Es muy interesante ésta investigación y muy necesario para el colectivo enfermero .R.4

Mi visión sobre el instrumento [...] me gustaría participar en el análisis que se haga de las respuestas [...] en algún encuentro o taller. R.1.

Manifestaciones que se interpretan como un aliciente a promover acciones en una dirección que logre sacar a la Historia del anonimato y ampliar las vías del conocimiento y la cultura enfermera.

12. SánchezS. Historia de la enfermería en Uruguay. Montevideo: Trilce; 2002.

13. Sabino C.A. El proceso de investigación. $2^{\mathrm{a}}$ ed. Buenos Aires: Lumen/Humanitas; 1996.

14. Rodríguez $\mathrm{G}$ et al. Metodología de la investigación cualitativa. $2^{\mathrm{a}}$ ed. Málaga: Aljibe; 1996.

15. Pourtois JP et al. Epistemología e instrumentación en ciencias humanas. Versión de Montserrat Kirchner. Barcelona: Herder; 1992.

16. Bardin L. Análisis de contenido. Traducción de César Suárez. $2^{\mathrm{a}}$ ed. Madrid: Ed AKAL; 1996.

17. Vilar P. Iniciación al vocabulario del análisis histórico. Traducción de M. Dolors Folch. $6^{a}$ ed. Barcelona: Crítica; 1999.

18. Bloch M. Introducción a la historia. $4^{\mathrm{a}}$ ed. México (DF): Fondo de Cultura Económica; 1996.

19. Bretón P. La utopía de la comunicación. Traducción de Paula Mahler. Buenos Aires: Nueva Visión SAIC; 2000.

20. Hobsbawm E. Sobre la historia. Traducción de Jordi Beltrán y Josefina Ruiz. Barcelona: Crítica; 1998.

21. Cárdenas L. La profesionalización de la enfermería en México. Un análisis desde la sociología de las profesiones. Barcelona: Ed Pomares; 2005.

22. Leddy $S$ et al. Bases conceptuales de la enfermería profesional. New York: JP Lippincott Company; 1989.

\section{Sobre la Autora}

\section{Nidia Hernández Suárez}

Miembro del Consejo Directivo del Colegio de Enfermeras del Uruguay. Profesora Emérita por la Universidad de la República. Investigadora en Historia de la Enfermería. Vencedora del Premio I Coloquio Latino Americano de Historia de la Enfermería. R. de Janeiro. 2000. 